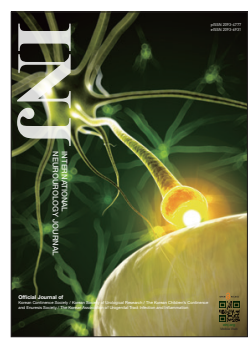

\title{
Clinical Efficacy of Solifenacin in the Management of Diabetes Mellitus-Associated Versus Idiopathic Overactive Bladder Symptoms: A Multicenter Prospective Study
}

\author{
Hoon $\mathrm{Choi}^{1}$, Jae Hyun Bae ${ }^{1}$, Cheol Young $\mathrm{Oh}^{2}$, Seong Jin Jeong ${ }^{3}$, Woo Jin $\mathrm{Ko}^{4}$, Jong Bo Choi ${ }^{5}$, Ju Tae $\mathrm{Seo}^{6}$, Dong Hwan Lee, \\ Joon Chul Kim ${ }^{8}$, Kwang Woo Lee', Young Ho Kim ${ }^{9}$ \\ ${ }^{1}$ Department of Urology, Korea University Hospital, Korea University College of Medicine, Ansan, Korea \\ ${ }^{2}$ Department of Urology, Hallym University College of Medicine, Chuncheon, Korea \\ ${ }^{3}$ Department of Urology, Seoul National University Bundang Hospital, Seongnam, Korea \\ ${ }^{4}$ Department of Urology, National Health Insurance Service Ilsan Hospital, Yonsei University College of Medicine, Goyang, Korea \\ ${ }^{5}$ Department of Urology, Ajou University College of Medicine, Suwon, Korea \\ ${ }^{6}$ Department of Urology, Cheil General Hospital and Women's Healthcare Center, Dankook University College of Medicine, Seoul, Korea \\ ${ }^{7}$ Department of Urology, Incheon St. Mary's Hospital, The Catholic University College of Medicine, Incheon, Korea \\ ${ }^{8}$ Department of Urology, Bucheon St. Mary's Hospital, College of Medicine, The Catholic University of Korea, Bucheon, Korea \\ ${ }^{9}$ Department of Urology, Soonchunhyang University Hospital, Soonchunhyang University College of Medicine, Bucheon, Korea
}

Purpose: To compare the clinical efficacy of anticholinergics for managing diabetes mellitus-associated overactive bladder (DM OAB) versus idiopathic overactive bladder $(\mathrm{OAB})$ in Korean women.

Methods: We conducted a multicenter, prospective, parallel-group, open-label, 12-week study. Women (20-65 years old) with $\mathrm{OAB}$ symptoms for over 3 months were assigned to the DM OAB and idiopathic OAB groups. Changes in the Overactive Bladder Symptom Score (OABSS), urgency, urinary urgency incontinence, nocturia, daytime frequency according to a voiding diary, uroflowmetry, and postvoid residual urine volume (PVR) at the first visit (V1), week 4 (V2), and week 12 (V3) were compared.

Results: No significant difference was found between the baseline patient characteristics of the DM OAB and idiopathic OAB groups. Treatment with solifenacin was associated with improvements in urgency, urinary urgency incontinence, nocturia, frequency according to a voiding diary, and the total OABSS between V1 and V2 and between V1 and V3. Moreover, a significant improvement in urgency and urge incontinence was found between V2 and V3 in the DM OAB group. However, no significant changes were found in any other parameters. There were no significant differences between the DM OAB group and the idiopathic $\mathrm{OAB}$ group except for urgency and urge incontinence at $\mathrm{V} 2$ (3.71 vs. 2.28 and 0.47 vs. 0.32 , respectively).

Conclusions: The patients who received solifenacin demonstrated improved urgency, urinary urgency incontinence, nocturia, frequency according to a voiding diary, and total OABSS. Management with solifenacin was equally effective for both DM-related $\mathrm{OAB}$ and idiopathic $\mathrm{OAB}$.

Keywords: Anticholinergics; Overactive urinary bladder; Diabetes mellitus

- Research Ethics: All procedures performed in studies involving human participants were in accordance with the ethical standards of the institutional and/or national research committee and with the 1964 Helsinki declaration and its later amendments (approval number: Korea University - AS 11175).

- Conflict of Interest: No potential conflict of interest relevant to this article was reported.

Corresponding author: Young Ho Kim (iD https://orcid.org/0000-0003-3959-0928 Department of Urology, Soonchunhyang University Bucheon Hospital, Soonchunhyang University College of Medicine, 170 Jomaru-ro, Wonmi-gu, Bucheon 14584, Korea

E-mail: yhkuro@schmc.ac.kr / Tel: +82-32-621-6561 / Fax: +82-32-460-8340

Submitted: September 5, 2017 / Accepted after revision: March 2, 2018
This is an Open Access article distributed under the terms of the Creative Commons Attribution Non-Commercial License (http://creativecommons.org/licenses/by-nc/4.0/) which permits unrestricted non-commercial use, distribution, and reproduction in any medium, provided the original work is properly cited. 


\section{INTRODUCTION}

Lower urinary tract symptoms (LUTS) are classified as storage symptoms, urinary symptoms, and postvoiding symptoms. Recent epidemiologic data have revealed that more than $64 \%$ of men over 40 years of age have at least 1 LUTS [1]. These symptoms impair the quality of life of elderly individuals and may lead to falls, skin infections, sleep disorders, and depression [2].

Among LUTS, storage symptoms are predominant (51\%), followed by voiding (26\%) and postvoiding symptoms (17\%), which are especially problematic.

The most common disease criterion is overactive bladder $(\mathrm{OAB})$, which is characterized by urinary frequency, urgency, nocturia, and urge incontinence. $\mathrm{OAB}$ is usually due to detrusor instability [3]. OAB occurs for various reasons, such as pregnancy, aging, childbirth, and infection, and may originate from neurologic problems such as those induced by diabetes mellitus (DM) or problems in the central nervous system [4].

DM affects many organs, resulting in many complications, the most important of which in urology is urinary bladder dysfunction due to diabetes [5].

Animal experimental studies have consistently shown that the induction of diabetes markedly affects the morphology, innervation, and function of the urinary bladder [6,7]. Studies have revealed that more than $80 \%$ of patients with diabetes have LUTS. Considering that $60 \%$ and $50 \%$ of patients with diabetes have neuropathy and renal complications, respectively, we can infer that DM exerts considerable effects on voiding function $[8,9]$.

DM bladder dysfunction refers to LUTS caused by DM, and it is characterized by decreased bladder sensation (bladder bloating), increased bladder sensitivity with inadequate contraction, decreased bladder contraction, and increased residual urine [10,11].

Although the medical use of anticholinergics for general $\mathrm{OAB}$ has gained universal acceptance, there is little specific motivation for its use in the treatment of DM-related bladder dysfunction, other than for idiopathic $\mathrm{OAB}$.

Although DM-related bladder dysfunction is not a lifethreatening disease, it has a serious negative impact on quality of life, with a relatively high prevalence of $32 \%-45 \%[12,13]$. LUTS can affect people of all ages, and their complications related to diabetes may be exacerbated during the aging process, resulting in a huge socioeconomic burden.

In this study, we compared the effects of solifenacin treat- ment on the improvement of LUTS between patients with idiopathic $\mathrm{OAB}$ and patients with $\mathrm{OAB}$ and $\mathrm{DM}$.

\section{MATERIALS AND METHODS}

From January 2012 to January 2014, we conducted a multicenter, prospective, parallel-group, open-label, 12-week study. Subjects included women aged 20-65 years who had experienced $\mathrm{OAB}$ symptoms for more than 3 months with an Overactive Bladder Symptom Score (OABSS) subscore for the third question of $\geq 2$, a total OABSS of $\geq 3$, and a $>8$ total micturition events per day on average during 3 days according to a voiding diary or at least 1 episode of urgent urinary incontinence. The DM patients that were included in the study were diagnosed by an endocrinologist and were under proper medical control.

Exclusion criteria were uncontrolled de novo DM, a urinary peak flow rate of $<12 \mathrm{~mL} / \mathrm{sec}$, PVR of $>20 \%$ of the voided urine or $>120 \mathrm{~mL}$, having undergone urologic surgery (including procedures for stress incontinence, cystitis, and pelvic prolapse) within the past 6 months, having undergone bladder training, or having taken an anticholinergic medication within the past 3 months.

Patients who took medications that could affect bladder function (anticholinergics, sympathomimetics, sympatholytics, calcium channel blockers, narcotics, antidepressants, antipsychotics, and diuretics) and patients with urinary tract infec-

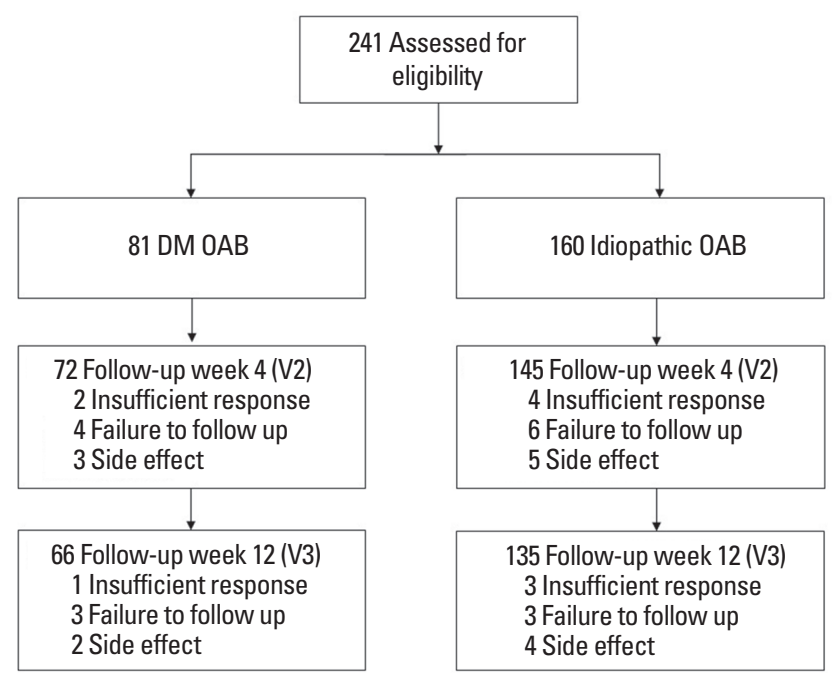

Fig. 1. Flow diagram of the study. $D M$, diabetes mellitus; $O A B$, overactive bladder; V2, week 4 (visit 2); V3, week 12 (visit 3). 
tions, interstitial cystitis, bladder stones, past pelvic radiotherapy, or a history of malignant disease were also excluded.

All subjects were assigned to the $\mathrm{DM} O \mathrm{OAB}$ group or the idiopathic $\mathrm{OAB}$ group according to their medical history. The study process is shown in Fig. 1.

All patients received $5 \mathrm{mg}$ of solifenacin once daily. Patients were allowed to increase or maintain their dose based on the choices made by the patients and their physicians regarding symptom improvement and tolerability.

The efficacy and adverse effects of solifenacin treatment were evaluated in the $\mathrm{DM} O A B$ and idiopathic $\mathrm{OAB}$ groups at the beginning of the study and at 4 and 12 weeks after the start of the study.

Changes in the average number of voiding times and number of urgency episodes were assessed by 3-day records of urination. Voiding diary records encompassing $>2$ days within 3 days were regarded as valid. Changes in clinical parameters such as the OABSS, urgency, urinary urgency incontinence, nocturia, frequency according to a voiding diary, uroflowmetry, and PVR at the first visit (V1), week 4 (V2), and week 12 (V3) were compared using descriptive analyses.

All values are expressed as mean with standard deviation. The significance of differences between the DM OAB and idiopathic OAB groups was determined using the Student $t$-test and repeated-measures analysis of variance, with differences considered significant at $\mathrm{P}<0.05$. All statistical analyses were performed using SPSS ver. 12.0 (SPSS Inc., Chicago, IL, USA).

\section{RESULTS}

Fig. 1 shows the reasons for participant drop-out in the present study. Among the 241 patients eligible for enrollment, 201 completed the study. The DM OAB group comprised 66 participants and the idiopathic $\mathrm{OAB}$ group contained 135.

There were no significant differences between the groups in baseline patient characteristics, including age, OABSS, and clinical parameters (Table 1).

The idiopathic OAB group showed improvements in urgency, urinary urgency incontinence, nocturia, frequency according to a voiding diary, and incontinence between V1 and V2 and between $\mathrm{V} 1$ and V3 with solifenacin treatment (Table 2).

Table 1. Baseline characteristics in the 2 groups

\begin{tabular}{lrrc}
\hline Characteristic & $\begin{array}{c}\text { DM OAB } \\
(\mathrm{n}=66)\end{array}$ & $\begin{array}{c}\text { Idiopathic OAB } \\
(\mathrm{n}=135)\end{array}$ & P-value \\
\hline Age $(\mathrm{yr})$ & $55.8 \pm 6.9$ & $55.5 \pm 7.1$ & 0.96 \\
OABSS total & $5.23 \pm 2.4$ & $5.01 \pm 2.2$ & 0.53 \\
Urgency & $6.60 \pm 4.1$ & $5.59 \pm 3.7$ & 0.56 \\
Urinary urgency incontiennce & $1.02 \pm 0.4$ & $0.89 \pm 0.3$ & 0.62 \\
Frequency & $8.61 \pm 2.4$ & $8.82 \pm 2.5$ & 0.88 \\
Nocturia & $1.76 \pm 0.9$ & $1.59 \pm 0.9$ & 0.23 \\
Qmax $(\mathrm{mL} / \mathrm{sec})$ & $19.83 \pm 9.6$ & $18.01 \pm 7.6$ & 0.42 \\
PVR $(\mathrm{mL})$ & $16.73 \pm 4.1$ & $18.38 \pm 4.5$ & 0.19 \\
\hline
\end{tabular}

Values are presented as mean \pm standard deviation.

$\mathrm{DM}$, diabetes mellitus; OAB, overactive bladder; OABSS, Overactive Bladder Symptom Score; Qmax, maximum flow rate; PVR, postvoid resirual urine.

Table 2. Comparision of follow-up visit results between $D M$ OAB group and idiopathic OAB group

\begin{tabular}{|c|c|c|c|c|}
\hline \multirow{2}{*}{ Variable } & \multicolumn{2}{|c|}{$\mathrm{V} 2$} & \multicolumn{2}{|c|}{$\mathrm{V} 3$} \\
\hline & DM OAB & idiopathic $\mathrm{OAB}$ & DM OAB & idiopathic $\mathrm{OAB}$ \\
\hline OABSS Total & $3.23 \pm 1.2^{\mathrm{a})}$ & $3.16 \pm 1.4^{\mathrm{a})}$ & $3.01 \pm 0.9^{\mathrm{b})}$ & $2.89 \pm 1.1^{\mathrm{b})}$ \\
\hline Urgency & $3.71 \pm 2.1^{\mathrm{a}, \mathrm{c}, \mathrm{d})}$ & $2.28 \pm 1.7^{\mathrm{a})}$ & $2.09 \pm 1.8^{\mathrm{b})}$ & $1.77 \pm 0.9^{\mathrm{b})}$ \\
\hline Urinary urgency incontiennce & $0.47 \pm 0.2^{\mathrm{a}, \mathrm{c}, \mathrm{d})}$ & $0.32 \pm 0.1^{\mathrm{a})}$ & $0.23 \pm 0.1^{\mathrm{b})}$ & $0.27 \pm 0.1^{\mathrm{b})}$ \\
\hline Frequency & $7.01 \pm 5.5^{\mathrm{a})}$ & $5.98 \pm 3.4^{\mathrm{a})}$ & $6.33 \pm 3.7^{\mathrm{b})}$ & $5.70 \pm 2.3^{\mathrm{b})}$ \\
\hline Nocturia & $1.36 \pm 0.1^{\mathrm{a})}$ & $1.24 \pm 0.4^{\mathrm{a})}$ & $1.15 \pm 0.4^{\mathrm{b})}$ & $0.85 \pm 0.3^{\mathrm{b})}$ \\
\hline $\operatorname{Qmax}(\mathrm{mL} / \mathrm{sec})$ & $15.26 \pm 6.5$ & $15.14 \pm 6.4$ & $13.86 \pm 6.7$ & $12.76 \pm 6.3$ \\
\hline $\operatorname{PVR}(\mathrm{mL})$ & $27.43 \pm 18.1$ & $29.97 \pm 19.4$ & $32.74 \pm 14.4$ & $36.36 \pm 17.3$ \\
\hline
\end{tabular}

Values are presented as mean \pm standard deviation.

DM, diabetes mellitus; OAB, overactive bladder; OABSS, Overactive Bladder Symptom Score; Qmax, maximum flow rate; PVR, postvoid resirual urine; V1, first visit (visit 1); V2, week 4 (visit 2); V3, week 12 (visit 3).

${ }^{\text {a) }} \mathrm{P}<0.05$, V1 vs. V2. ${ }^{\text {b) }} \mathrm{P}<0.05$, V1 vs. V3. ${ }^{\text {c) }} \mathrm{P}<0.05$, V2 vs. V3. ${ }^{\text {d) }} \mathrm{P}<0.05$, DM OAB vs. idiopathic OAB.

The results of $\mathrm{V} 1$ is expressed in Table 1 . 

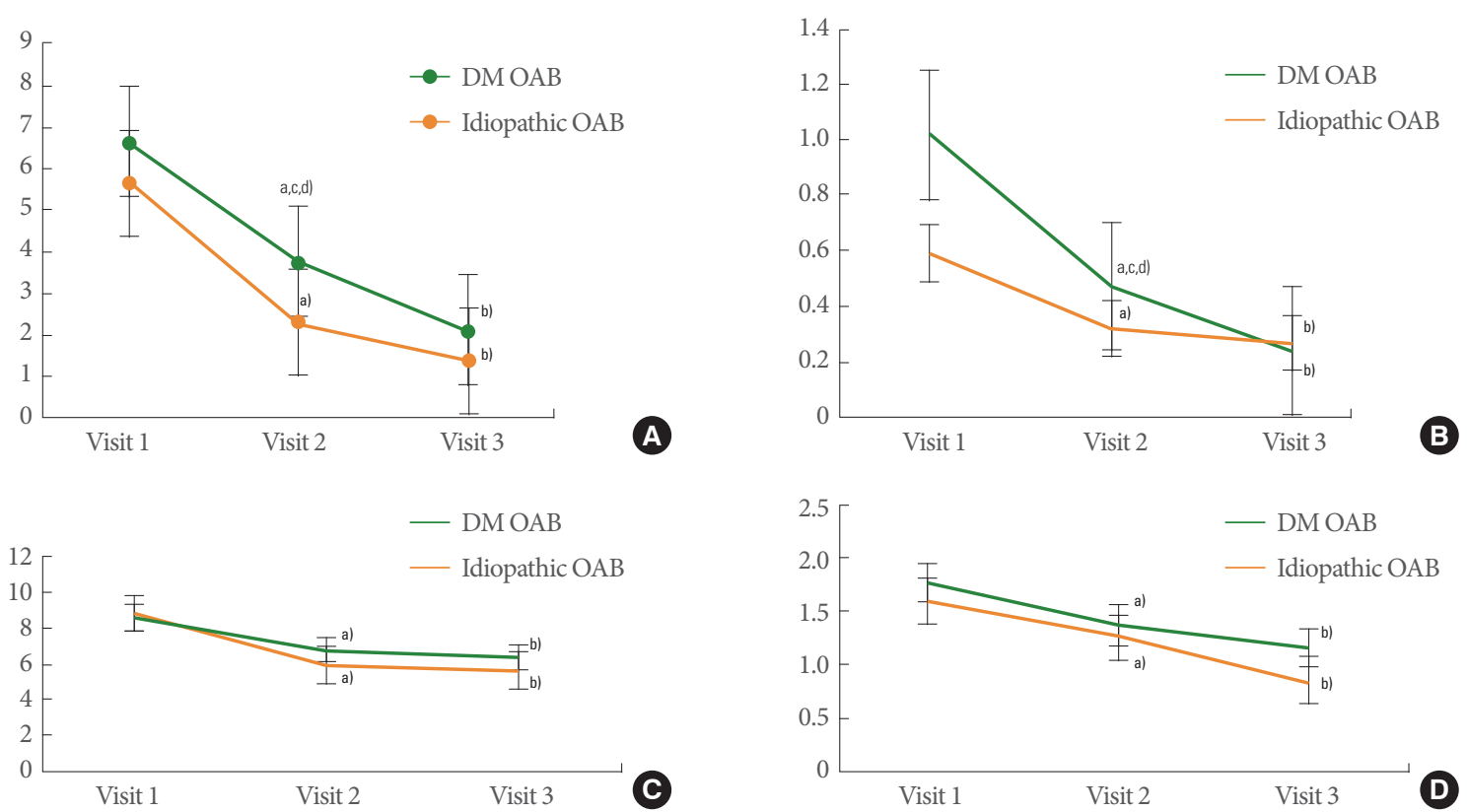

Fig. 2. Serial changes parameters in diabetes mellitus-associated overactive bladder (DM OAB) and idiopathic OAB at each time point. (A) Urgency. (B) Urge incontinence. (C) Frequency. (D) Night frequency. V1, first visit (visit 1); V2, week 4 (visit 2); V3, week 12 (visit 3). ${ }^{\text {a) }} \mathrm{P}<0.05$, V1 vs. V2. ${ }^{\text {b) }} \mathrm{P}<0.05$, V1 vs. V3. ${ }^{\text {c) }} \mathrm{P}<0.05, \mathrm{~V} 2$ vs. V3. ${ }^{\text {d) }} \mathrm{P}<0.05$, DM OAB vs. idiopathic OAB.

No changes were found in any other parameters (Fig. 2).

The DM OAB group also demonstrated improvements in urgency, urinary urgency incontinence, frequency according to a voiding diary, and incontinence between V1 and V2 and between V1 and V3 (Fig. 2).

Urgency significantly improved from 3.71 to 2.09 , and urinary urgency incontinence also improved from 0.47 to 0.23 in the DM OAB group between V2 and V3 (Fig. 2A, B).

Furthermore, there were no significant differences between the DM OAB group and idiopathic OAB group at each visit. Only urgency and urinary urgency incontinence at V2 showed a statistically significant difference (3.71 vs. 2.28 and 0.47 vs. 0.32) (Fig. 2A, B).

\section{DISCUSSION}

DM is generally considered a specific risk factor for voiding dysfunction. Prior studies have demonstrated contradictory outcomes regarding the relationship between DM and OAB [14].

In a previous study, detrusor overactivity was observed in $38.5 \%$ of DM patients and various urodynamic findings were observed [15]. In another report, the overall prevalence of OAB in $\mathrm{DM}$ patients was as high as $24.8 \%$, and $\mathrm{OAB}$ increased with aging and duration of diabetes [16]. Several studies also showed positive associations with age, but other factors, such as body mass index or metabolic syndrome, did not contribute to the development of OAB $[17,18]$.

Furthermore, Palleschi et al. [19] found that OAB was more common in patients with DM, but there was no statistically significant difference in the OAB-questionnaire scores and glycosylated hemoglobin levels in DM patients.

Among the $\mathrm{OAB}$ symptoms, urgency was more frequently observed in patients with DM (28.0\%) than in those without DM (16.3\%) [20]. Men with DM had worse OABSS and International Prostate Symptom Scores than controls, especially for storage domain symptoms because of their higher frequency and nocturia subscores [21]. Consequently, it is evident that $\mathrm{OAB}$, including storage symptoms, is associated with DM [20].

Some hypotheses have been proposed to explain the association between DM and OAB. First, hyperglycemia induces hyperosmolality, causing polydipsia and polyuria; then, the typical storage symptoms of frequency and nocturia result from DM.

Storage symptoms may be explained by the influence of chronic DM on the nervous system via forms of neuropathy. Altered glucose metabolism and tissue ischemia via superoxideinduced free-radical creation and damage to the axonal transport system are all possible mechanisms through which DM 
leads to peripheral neuropathy [22]. Due to injuries to the parasympathetic and, most likely, sympathetic nerve denervation of the detrusor muscle, deterioration of contraction and compliance can be predicted $[23,24]$.

DM is a significant risk factor for atherosclerosis with consequent organ ischemia, which also induces detrusor overactivity. Isolated bladder muscle strips from rats with DM demonstrated impulsive muscle contractility that was not observed in normal rat bladder, and the bladder tissues from the rats with DM were supersensitive to synthetic cholinergics, even though there was no alteration in the maximum response to carbachol [25].

Regarding atherosclerosis, both central and peripheral mechanisms may be involved in the occurrence of $\mathrm{OAB}$ in $\mathrm{DM}$ patients. Via DM-related atherosclerotic vasculopathy, multiple cerebral infarctions and bladder ischemia could take place, inducing detrusor overactivity and increased bladder sensation as a result of central and peripheral nerve injuries [26]. Another possible mechanism is based on inflammation. DM may cause tissue inflammation that enhances fibrosis in the urinary tract, eventually inducing LUTS.

Considering the physiological changes associated with DM, it is important to understand how DM patients with $\mathrm{OAB}$ respond to $\mathrm{OAB}$ management. In general, anticholinergic medications are the cornerstone of $\mathrm{OAB}$ management [27]. From the histologic and physiological changes in the diabetic bladder, we can infer that $\mathrm{OAB}$ patients with $\mathrm{DM}$ experience more LUTS and associated difficulties than those without concomitant DM.

However, few studies have investigated the difference between $\mathrm{DM}$-associated $\mathrm{OAB}$ and other $\mathrm{OAB}$ types. In a previous study of the effects of darifenacin, a representative muscarinic antagonist, the treatment responses were slightly but significantly smaller in DM patients than in controls, but the differences were only small relative to the overall treatment effect. Furthermore, tolerability and side effects were similar between the 2 groups [28].

The present study also revealed that anticholinergics are equally effective, irrespective of the presence of DM. The DM $\mathrm{OAB}$ group showed improvements in urgency, urge incontinence, and night frequency equivalent to those observed in the idiopathic $\mathrm{OAB}$ group.

The role of diabetes in voiding dysfunction may be explained by DM-related bladder hypertrophy and dysfunction, which may manifest differentially over time, as contractility and responsiveness to contractile stimuli appear to increase in diabet- ic bladder smooth muscle at early time points, and this trend can turn into hyporesponsiveness in late stages of the disease over time. However, this is manageable upon normalization of blood glucose via treatment and appropriate medical control [29-31].

Despite concerns regarding DM-related pathologic changes in the bladder, we observed that anticholinergics could control $\mathrm{OAB}$ in patients with well-controlled DM. Most of the patients in our study had well-controlled diabetes because we excluded cases of uncontrolled de novo DM.

The patients in the DM OAB group showed a more delayed therapeutic response, because urgency and urge incontinence also improved between V2 and V3 in the DM OAB group, with distinct differences in urgency and urge incontinence at $\mathrm{V} 2$ between the $\mathrm{DM} O \mathrm{OAB}$ group and the idiopathic $\mathrm{OAB}$ group. We may thus infer that $\mathrm{DM}$ patients take longer to respond to $\mathrm{OAB}$ medication, possibly because of the negative physiological effects of DM.

Of note, our multicenter study was the first to differentiate a serial change in the response to anticholinergics in $\mathrm{DM} O \mathrm{OAB}$ and idiopathic $\mathrm{OAB}$ patients.

However, the study had some limitations because the $\mathrm{OAB}$ diagnosis in the clinical setting was not derived from the demonstration of detrusor overactivity through urodynamic tests. Moreover, only data collected from a voiding diary and self-reported OABSS questionnaires were available, although there are other useful parameters in this field. Comorbid factors, excluding diabetes that may have affected voiding function and urine volume were not analyzed. Systemic parameters, such as high blood pressure, stroke, hypertension, obesity, albuminuria, high creatinine levels, a low glomerular filtration rate, and lower hemoglobin levels, are risk factors for LUTS [32-34]. More importantly, no related analysis was conducted between $\mathrm{OAB}$ symptoms and parameters relevant to diabetes, such as the sufficiency of diabetes management as assessed using hemoglobin Alc levels. Data on the duration of DM morbidity and the severity of DM were also lacking. Because of the limited nature of our study, we could not reach definitive conclusions on the absolute efficacy or tolerability of anticholinergics in $\mathrm{OAB}$ patients with DM.

However, this study provides some information on the response to a muscarinic receptor antagonist in patients with diabetes versus those without diabetes. We may conclude that a muscarinic receptor antagonist has equivalent efficacy and tolerability for the treatment of $\mathrm{OAB}$ patients with and without 
concomitant diabetes. Larger, well-designed studies should provide more detailed analyses, while taking into account patients' diabetes-related history to identify better methods to control OAB in patients with DM.

In conclusion, patients who received solifenacin demonstrated improved urgency, urge incontinence, nocturia, frequency according to a voiding diary, and incontinence. Management with solifenacin was equally effective for both DM-related $O A B$ and idiopathic $\mathrm{OAB}$.

\section{AUTHOR CONTRIBUTION STATEMENT}

- Full access to all the data in the study and takes responsibility for the integrity of the data and the accuracy of the data analysis: $\mathrm{H}$ Choi

- Study concept and design: JH Bae

- Acquisition of data: $\mathrm{CYOh}$

- Analysis and interpretation of data: SJ Jeong

- Drafting of the manuscript: WJ Ko

-Critical revision of the manuscript for important intellectual content: JB Choi

- Statistical analysis: JT Seo

- Obtained funding: $\mathrm{DH}$ Lee

- Administrative, technical, or material support: JC Kim, KW Lee

-Study supervision: YH Kim

\section{REFERENCES}

1. Yalla SV, Sullivan MP, Lecamwasam HS, DuBeau CE, Vickers MA, Cravalho EG. Correlation of American Urological Association symptom index with obstructive and nonobstructive prostatism. J Urol 1995;153(3 Pt 1):674-9.

2. Jackson $S$. The patient with an overactive bladder: symptoms and quality-of-life issues. Urology 1997;50(6A Suppl):18-22.

3. Milsom I, Abrams P, Cardozo L, Roberts RG, Thüroff J, Wein AJ. How widespread are the symptoms of an overactive bladder and how are they managed? A population-based prevalence study. BJU Int 2001;87:760-6.

4. Brown JS, Seeley DG, Fong J, Black DM, Ensrud KE, Grady D. Urinary incontinence in older women: who is at risk? Study of Osteoporotic Fractures Research Group. Obstet Gynecol 1996;87(5 Pt 1):715-21.

5. Kim JC, Seo SI, Park YH, Hwang TK. Changes of detrusor contractility and growth factors in streptozotocin-induced. Korean J Urol
2000;41:615-21.

6. Daneshgari F, Liu G, Birder L, Hanna-Mitchell AT, Chacko S. Diabetic bladder dysfunction: current translational knowledge. J Urol 2009;182(6 Suppl):S18-26.

7. Golbidi S, Laher I. Bladder dysfunction in diabetes mellitus. Front Pharmacol 2010;1:136.

8. Wetle T, Scherr P, Branch LG, Resnick NM, Harris T, Evans D, et al. Difficulty with holding urine among older persons in a geographically defined community: prevalence and correlates. J Am Geriatr Soc 1995;43:349-55.

9. Brown JS, Grady D, Ouslander JG, Herzog AR, Varner RE, Posner SF. Prevalence of urinary incontinence and associated risk factors in postmenopausal women. Heart \& Estrogen/Progestin Replacement Study (HERS) Research Group. Obstet Gynecol 1999;94:6670.

10. Frimodt-Møller C. Diabetic cystopathy: epidemiology and related disorders. Ann Intern Med 1980;92(2 Pt 2):318-21.

11. Yoshimura N, Chancellor MB, Andersson KE, Christ GJ. Recent advances in understanding the biology of diabetes-associated bladder complications and novel therapy. BJU Int 2005;95:733-8.

12. Kaplan SA, Te AE, Blaivas JG. Urodynamic findings in patients with diabetic cystopathy. J Urol 1995;153:342-4.

13. Brown JS, Nyberg LM, Kusek JW, Burgio KL, Diokno AC, Foldspang A, et al. Proceedings of the National Institute of Diabetes and Digestive and Kidney Diseases International Symposium on epidemiologic issues in urinary incontinence in women. Am J Obstet Gynecol 2003;188:S77-88.

14. Lee WC, Wu HP, Tai TY, Yu HJ, Chiang PH. Investigation of urodynamic characteristics and bladder sensory function in the early stages of diabetic bladder dysfunction in women with type 2 diabetes. J Urol 2009;181:198-203.

15. Bansal R, Agarwal MM, Modi M, Mandal AK, Singh SK. Urodynamic profile of diabetic patients with lower urinary tract symptoms: association of diabetic cystopathy with autonomic and peripheral neuropathy. Urology 2011;77:699-705.

16. Liu RT, Chung MS, Lee WC, Chang SW, Huang ST, Yang KD, et al. Prevalence of overactive bladder and associated risk factors in 1359 patients with type 2 diabetes. Urology 2011;78:1040-5.

17. Cheung WW, Blank W, Borawski D, Tran W, Bluth MH. Prevalence of overactive bladder, its under-diagnosis, and risk factors in a male urologic veterans population. Int J Med Sci 2010;7:391-4.

18. Ohgaki K, Horiuchi K, Kondo Y. Association between metabolic syndrome and male overactive bladder in a Japanese population based on three different sets of criteria for metabolic syndrome and the Overactive Bladder Symptom Score. Urology 2012;79:1372-8. 
19. Palleschi G, Pastore AL, Maggioni C, Fuschi A, Pacini L, Petrozza $\mathrm{V}$, et al. Overactive bladder in diabetes mellitus patients: a questionnaire-based observational investigation. World J Urol 2014; 32:1021-5.

20. Chiu AF, Huang MH, Wang CC, Kuo HC. Higher glycosylated hemoglobin levels increase the risk of overactive bladder syndrome in patients with type 2 diabetes mellitus. Int J Urol 2012;19:9951001.

21. Bang WJ, Lee JY, Koo KC, Hah YS, Lee DH, Cho KS. Is type-2 diabetes mellitus associated with overactive bladder symptoms in men with lower urinary tract symptoms? Urology 2014;84:670-4.

22. Apfel SC. Neurotrophic factors and diabetic peripheral neuropathy. Eur Neurol 1999;41 Suppl 1:27-34.

23. Oztürk Y, Altan VM, Yildizoğlu-Ari N. Effects of experimental diabetes and insulin on smooth muscle functions. Pharmacol Rev 1996;48:69-112.

24. Turner WH, Brading AF. Smooth muscle of the bladder in the normal and the diseased state: pathophysiology, diagnosis and treatment. Pharmacol Ther 1997;75:77-110.

25. Stevens LA, Sellers DJ, McKay NG, Chapple CR, Chess-Williams R. Muscarinic receptor function, density and G-protein coupling in the overactive diabetic rat bladder. Auton Autacoid Pharmacol 2006;26:303-9.

26. Yamaguchi C, Sakakibara R, Uchiyama T, Yamamoto T, Ito T, Liu Z, et al. Overactive bladder in diabetes: a peripheral or central mechanism? Neurourol Urodyn 2007;26:807-13.

27. Chapple CR, Khullar V, Gabriel Z, Muston D, Bitoun CE, Weinstein $\mathrm{D}$. The effects of antimuscarinic treatments in overactive bladder: an update of a systematic review and meta-analysis. Eur Urol 2008;54:543-62.

28. Schneider T, Marschall-Kehrel D, Hanisch JU, Michel MC. Does concomitant diabetes affect treatment responses in overactive bladder patients? Int J Clin Pract 2013;67:1138-43.

29. Yono M, Pouresmail M, Takahashi W, Flanagan JF, Weiss RM, Latifpour J. Effect of insulin treatment on tissue size of the genitourinary tract in $\mathrm{BB}$ rats with spontaneously developed and streptozotocin-induced diabetes. Naunyn Schmiedebergs Arch Pharmacol 2005;372:251-5.

30. Christ GJ, Hsieh Y, Zhao W, Schenk G, Venkateswarlu K, Wang $\mathrm{HZ}$, et al. Effects of streptozotocin-induced diabetes on bladder and erectile (dys)function in the same rat in vivo. BJU Int 2006; 97:1076-82.

31. Tong YC, Cheng JT. Changes in bladder nerve-growth factor and p75 genetic expression in streptozotocin-induced diabetic rats. BJU Int 2005;96:1392-6.

32. Wu MY, Wu YL, Hsu YH, Lin YF, Fan YC, Lin YC, et al. Risks of nocturia in patients with chronic kidney disease--do the metabolic syndrome and its components matter? J Urol 2012;188:2269-73.

33. Kupelian V, McVary KT, Barry MJ, Link CL, Rosen RC, Aiyer LP, et al. Association of $\mathrm{C}$-reactive protein and lower urinary tract symptoms in men and women: results from Boston Area Community Health survey. Urology 2009;73:950-7.

34. Chung MS, Chuang YC, Lee JJ, Lee WC, Chancellor MB, Liu RT. Prevalence and associated risk factors of nocturia and subsequent mortality in 1,301 patients with type 2 diabetes. Int Urol Nephrol 2014;46:1269-75. 